\title{
3D in-Situ Stress Model of Upper Tamakoshi Hydroelectric Project Area
}

Chhatra Bahadur Basnet and Krishna Kanta Panthi

Chhatra Bahadur Basnet Krishna Kanta Panth

Abstract: Reliable estimation of in-situ stress state is very important in implementing the shotcrete lined/ unlined tunnels and shafts. The in-situ stress state of the area of concern is mainly governed by the gravityinduced stress, tectonic activity of the earth's crust and topographic condition of that area. The local tectonic and geological environment such as faulting and shearing activities in general influences the magnitude of tectonic stress level. The Himalayan region is renowned with its active tectonic movement (earthquake activities), which causes accumulation and sudden release of strain energy instigating changes in the stress environment. This paper aims to evaluate in-situ stress state at the Upper Tamakoshi Hydroelectric Project, where shotcrete lined/ unlined headrace tunnel with considerable hydrostatic head is being implemented. A detailed assessment of the in-situ stress state is carried out by using both measured data and threedimensional numerical analysis using FLAC3D.

Keywords: Himalayan geology and tectonics, in-situ stress, 3D model, topography, Upper Tamakoshi Hydroelectric Project, Nepal

\section{Introduction}

$\mathrm{U}$ nlined high pressure tunnels/shafts are used in the hydropower projects worldwide. Especially in Norway, more than $95 \%$ of the total water tunnels/ shafts are unlined. Such tunnels and shafts in Norway were considered to be possible due to the favorable engineering geological and tectonic conditions that persist in this region (Buen, 1984; Panthi, 2014). During the process of design, construction and operation of such tunnels, Norway has gradually developed different design criterion from time to time in the history (Selmer-Olsen, 1969; Broch, 1982 and BerghChristensen, 1982; Buen and Palmostrom, 1982). The state-of-the-art principle is that the in-situ minimum principal stress should be higher than the hydrostatic head acting on the periphery of unlined tunnel/shaft (Broch, 1982; Panthi, 2014). The correct evaluation of in-situ stresses is the key for the successful design of unlined pressure tunnel/shaft.

According to different authors (Broch, 1984; and Amadei and Ernian, 1995 among the others), there is an influence of topography in the in-situ stress development near earth surface where the unlined pressure tunnels are located. One of the earliest attempts to estimate the topographic stress was finite element method proposed by Selmer-Olsen (1974). However, this method considers 2D analysis, which does not represent complex topography especially nearby confluence of deep valleys. Similarly, Broch (1984) highlighted that the topographic correction is needed in order to define new rock mass over burden, which may underestimate the in-situ stress state. In addition, there have been several attempts to estimate in-situ stresses analytically in case of irregular topography. Amadei and Ernian (1995) proposed an analytical solution in order to estimate in-situ stress in rock mass considering both smooth and irregular topographies. Their method has limited application for both isotropic and anisotropic rock mass subject to gravitational and tectonic loading since the method is two-dimensional and hence cannot be used to analyze three-dimensional stress state.

The aim of this paper is to investigate on the influence of topography in rock stress situation. For this, Upper Tamakoshi Hydroelectric Project of Nepal Himalaya has been taken as case study and assessment has been made using three-dimensional numerical model (FLAC3D) and field measured in-situ stress data. While doing so the rock mass is considered homogeneous material, which may cause some uncertainty in our assessment and hence, future evaluation will be made in the near future to further enhance the result where consideration will be made to incorporate local shear bands of schistosity.

\section{Upper Tamakoshi Project}

Upper Tamakoshi Hydroelectric Project (UTHEP) is located in Dolakha district of Nepal, which is NorthEast of Kathmandu valley (Figure 1). The first phase of the project is in under construction where it is planned to use water only from Tamakoshi River to generate the power. While in the second phase water from Rolwaling Khola will also be added to the intake of Upper Tamakoshi located at Lamabagar. All together the project will have an installed capacity of $456 \mathrm{MW}$ and will exploit $66 \mathrm{~m} 3 / \mathrm{sec}$ design discharge and $822 \mathrm{~m}$ gross head (Reimer and Bock, 2013). The project consists of different headworks structures, headrace tunnel, vertical penstock shafts, and underground power station, tailrace and access tunnels. The pressurized headrace tunnel ends at the top of the upper vertical penstock shaft and is planned to be unlined/shotcrete lined tunnel.

\section{Geology and Tectonics}

Geologically, the project is located in the Higher Himalayan Tectonic Formation of eastern Nepal 
Himalaya (Figure 1). Rock mass in this formation is mainly characterized by Precambrian high grade metamorphic rocks such as gneiss, quartzite, marbles, magmatite and granitic gneiss of quality comparable to the Scandinavian hard rocks.

It is important that the geotectonic environment of the areas is well understood before numerical modeling to find out the in-situ stress state of the project area. It is well known fact that the uplift of the Himalayan and the Tibetan plateau was due to the collision of Indian and Euro-Asian continental plates, which took place some $100 \mathrm{Ma}$, where the Indian plate from the south is underthrusting the upper crust of the Euro-Asian plate. is shown in Figure 2 and Figure 3 respectively.

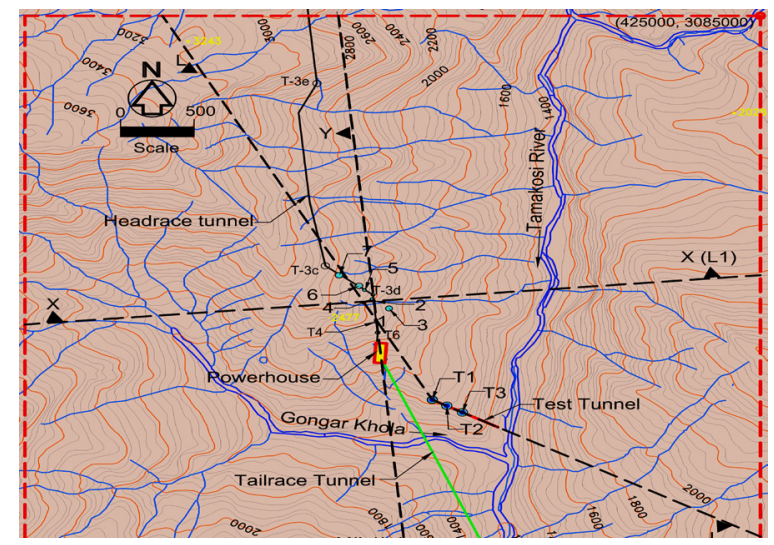

Figure 2: Topographic map of the project area showing the project layout and stress measurement locations

Several detail geological investigations have been carried out during planning and construction phases to come up to the latest version of alignment. One of the key parameters for the selection of headrace tunnel alignment was in-situ stress measured in different times by using $3 \mathrm{D}$ over coring at the bottom of the valley near powerhouse and by using hydraulic fracturing technique inside the topographic slope where headrace tunnel is aligned. Figure 2 and Figure 3 show the stress measurement locations.
Figure 1: Geological Map of Nepal Himalaya with project location

Due to this collision and under-thrusting, the upper part of the Indian crust near the plate boundary had been squeezed and became short and thick due to push from Euro-Asian (Tibetian) upper crust. This resulted to the number of tectonic rupture zones such as Main frontal Thrust (MFT), Main Boundary Thrust (MBT) and Main Central Thrust (MCT) as shown in figure 1 (Upreti, 1999; Jackson et al., 2008 and Rowley, 1996).

Hence, the Himalayan region is being undergoing persistent compression and the rate of convergence is estimated to be about $5 \mathrm{~cm} /$ year (Bird, 1978). The considerable amount of energy is being accumulated through this compressional process and the accumulated energy is being released through the rupture of tectonic faults and fractures during the occurrence of earthquakes. Owing to this situation of the Himalayan tectonics, it can be said that this region has quite complex tectonic stress regime in terms of both space and time.

\section{Stress State at the Project}

From pre-feasibility study in 2001 to date, there have been several changes on the headrace tunnel alignment of Upper Tamakoshi Hydroelectric Project, which is discussed in detail by Basnet and Panthi (2016). The latest version of plan and profile of the tunnel alignment

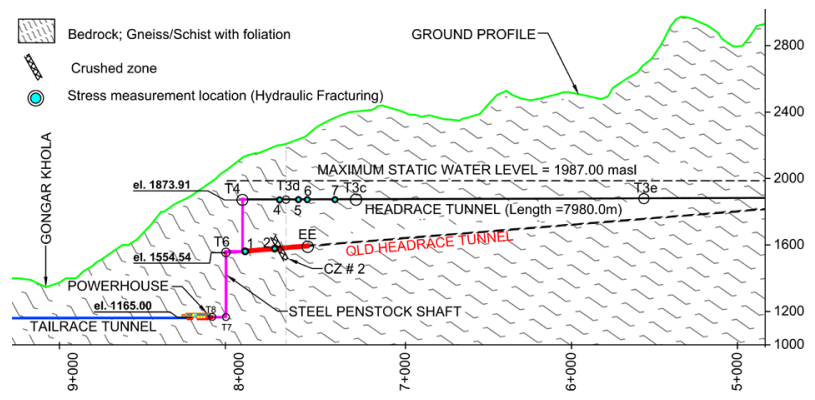

Figure 3: Geological and tunnel alignment profile showing stress measurement location

\section{D over coring}

In 2008, SINTEF carried out 3D over coring at three different locations of the test tunnel near powerhouse to find out the magnitude and orientation of in-situ stress state (the test locations are shown in Figure 2). These locations are situated at the bottom of the valley at an elevation of about 1250masl. Test results of the in-situ stress state are shown in Table 1.

\section{Hydraulic Fracturing}

For the first time in 2013, minimum principal stress was measured by using hydraulic fracturing technique at locations 1 and 2 of old headrace tunnel as shown in Figure 2 and Figure 3. In 2014, further measurements were made at locations 3, 4, 5 and 6 of the newly aligned 
headrace tunnel alignment. In addition, hydraulic fracturing test was carried out at location 7 in 2015. All the measurement locations are shown in Figure 2 and Figure 3 (location 3 is not in Figure 3) and the achieved test results are presented in Table 2. with measured stress at respective locations.

\section{Geometry and Grid Generation}

A 3D ground surface was created based on the contour information given in Figure 2. Two solid objects above

\begin{tabular}{|c|c|c|c|c|c|c|c|c|c|c|}
\hline \multirow[b]{2}{*}{ Stresses } & \multicolumn{3}{|c|}{ T1 } & \multicolumn{3}{|c|}{ T2 } & \multicolumn{3}{|c|}{ T3 } & \multirow{2}{*}{$\begin{array}{l}\text { and below } \\
\text { the ground } \\
\mathrm{s} \text { u r f a c e } \\
\text { were drawn }\end{array}$} \\
\hline & MPa & Trend & \begin{tabular}{|l|}
$\begin{array}{l}\text { Plunge } \\
\text { (deg.) }\end{array}$ \\
\end{tabular} & MPa & Trend & \begin{tabular}{|l|} 
Plunge \\
(deg.)
\end{tabular} & $\mathrm{MPa}$ & Trend & $\begin{array}{l}\text { Plunge } \\
\text { (deg.) }\end{array}$ & \\
\hline S1 & $18.4 \pm 2.9$ & $\mathrm{~N} 120.50 \mathrm{E}$ & 27.9 & $17.4 \pm 2.2$ & N204.60E & 30.3 & $21.6 \pm 2.2$ & $\mathrm{~N} 21.10 \mathrm{E}$ & 10.4 & with \\
\hline $\mathrm{S} 2$ & $12.4 \pm 4.7$ & N239.50E & 42.5 & $10.8 \pm 1.7$ & N100.20E & 23 & $12.6 \pm 2.8$ & N116.50E & 27.2 & $\begin{array}{l}\text { upper } \\
\text { level }\end{array}$ \\
\hline S3 & $7.1 \pm 1.8$ & N9.00E & 34.7 & $1.1 \pm 2.7$ & N339.40E & 50.4 & $6.4 \pm 2.7$ & $\mathrm{~N} 272.20 \mathrm{E}$ & 60.6 & the box as \\
\hline
\end{tabular}

Note: S1, S2 and S3 are major, intermediate and minor principal stresses respectively

Table 1: Stress measurement in Test Tunnel by 3D over coring (SINTEF, 2008)

\begin{tabular}{|c|c|c|c|c|}
\hline \multirow{2}{*}{ Location } & \multicolumn{5}{|c|}{ Minor principal stress (Mpa) } \\
\cline { 2 - 5 } & min. & avg. & max & Sd* \\
\hline $1^{\mathrm{a}}$ & 1.5 & 5.4 & 9.1 & \\
\hline $2^{\mathrm{a}}$ & 1.6 & 3.2 & 4.9 & \\
\hline $3^{\mathrm{b}}$ & 2.5 & 3.8 & 5.4 & 1.1 \\
\hline $4^{\mathrm{b}}$ & 4.2 & 4.4 & 4.6 & 0.3 \\
\hline $5^{\mathrm{b}}$ & & 3.6 & & \\
\hline $6^{\mathrm{b}}$ & 3.2 & 4.1 & 5.5 & 0.8 \\
\hline $7^{\mathrm{c}}$ & 2.8 & 6.2 & 11.9 & 3.5 \\
\hline
\end{tabular}

a SINTEF (2013), ' $M S G$ (2014), ' MSG (2015)

*Standard deviation

Table 2: Stress measurement by hydraulic fracturing

\section{Stress State Analysis}

FLAC3D (ITASCA, 2017) has been used to analyze the 3D state of in-situ stress of the project area (red dotted square in Figure 2). The plan area of the selected part is 5000m $\mathrm{x}$ 5000m.

\section{Modeling setup}

A 3 D box of the size $5000 m \times 5000 m \times$ $3850 m$ was created, which incorporates the topography shown in Figure 2. The mass above the topography was considered as eroded rock mass body over the past geologic period and was grouped with separate group name. First of all, the stresses including tectonic stress was initialized in each zone for whole box and the model was run for initial state. Once the model converged to the equilibrium within prescribed limit of unbalanced force, the rock mass above the real surface topography was excavated and the model was run once again until the second equilibrium state was reached. After the second equilibrium state, the model was considered to be ready for in-situ stress evaluation. The model was run for different tectonic stress level and orientations so that the output results were comparable and lowest level as at omasl. The lowest level was decided considering the fact that Indian plate is flat and the horizontal tectonic push is close to uniform and horizontal. Similar logic was also used by Bird (1978). The lower part was divided into three different solid objects, which were grouped as 'Rockmass1', 'Rockmass2' and 'Rockmass3'; and upper part was grouped as 'Rockmass4'. 'Rockmass1' covers the area of 2000m x 2000m including stress measurement locations and Rockmass2 surrounds the first one and has lowest elevation of 100omasl. Rockmass 3 represents from 10oomasl up to omasl. All four solid objects were divided into small zones with tetrahedron shapes. Rockmass1 was built in such a way that it has smaller zones with finer grids whereas Rockmass2 has finer grids nearby the first one and coarser in the remaining part. Rockmass3 and Rockmass4 were built in relatively bigger zones with coarser grids. The geometry, grids and zones are shown in Figure 4 where all groups of rock mass are indicated.

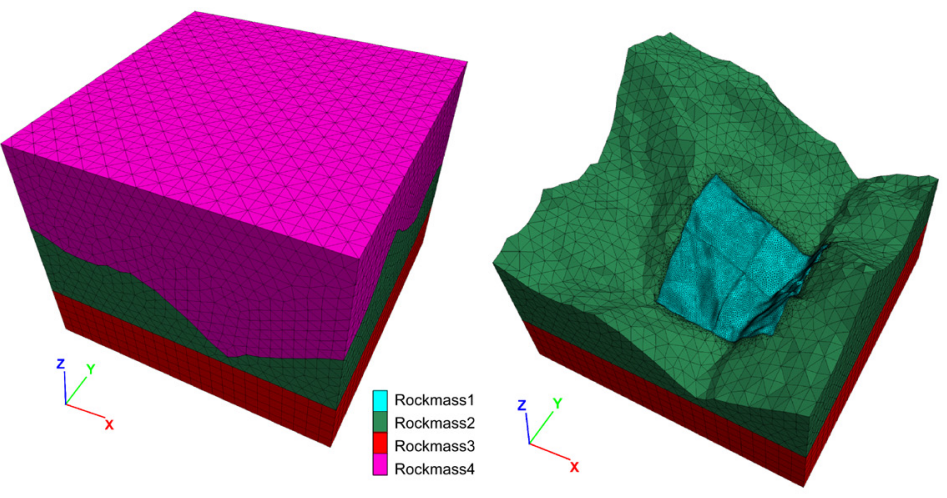

Figure 4: 3D geometry and mesh above ground surface before (left) and after excavation (right).

\section{Rock mechanical properties}

Rock mass strength and deformability properties are the key input parameters to numerical modelling. List of these parameters and mean values of the result from laboratory test are presented in Table 3 . The geological strength index is estimated based on the information from the project and other input values in Table 3 are calculated using RocData (Rocscience, 2017). Mohr- 
coulomb constitutive model was applied for numerical modeling in $\mathrm{FLAC}_{3} \mathrm{D}$.

\begin{tabular}{|l|c|c|}
\hline Parameters & Unit & Values \\
\hline Densitya, $\mathrm{Y}$ & $\mathrm{kg} / \mathrm{m}^{3}$ & 2745 \\
\hline Poisson's ratioa, v & & 0.2 \\
\hline Elasticity modulusa, E & $\mathrm{Gpa}$ & 30.2 \\
\hline Intact rock strengtha (UCS) & $\mathrm{Mpa}$ & 61 \\
\hline Bulk Modulus, K & $\mathrm{GPa}$ & 16.8 \\
\hline Shear Modulus, G & $\mathrm{GPa}$ & 12.6 \\
\hline Geological Strength Index & & 75 \\
\hline Material constant ${ }^{\mathrm{b}}$ mi & & 28 \\
\hline Friction angle & & 46.77 \\
\hline Cohesion & & 5.86 \\
\hline Tension & & \\
\hline $\begin{array}{l}\text { alaboratory test result; bestimated } \\
\text { using RocData }\end{array}$ & Mpg & -0.331 \\
\hline
\end{tabular}

Table 3: Input rock mechanical parameters to the model

\section{Stress}

Stress is another key input parameter to $\mathrm{FLAC}_{3} \mathrm{D}$. The stress along $\mathrm{Z}$-axis is mainly due to the vertical overburden of the rock mass, which was calculated by using eq. 1.

$$
\sigma_{z}=\gamma h
$$

Where, $\gamma$ is specific weight of rock mass and $h$ is overburden depth from the surface to the point of consideration. The horizontal stress due to vertical overburden was estimated by using eq. 2 .

$$
\sigma_{h}=\frac{v}{1-v} \gamma h
$$

Where $v$ is Poisson's ratio of the rock mass

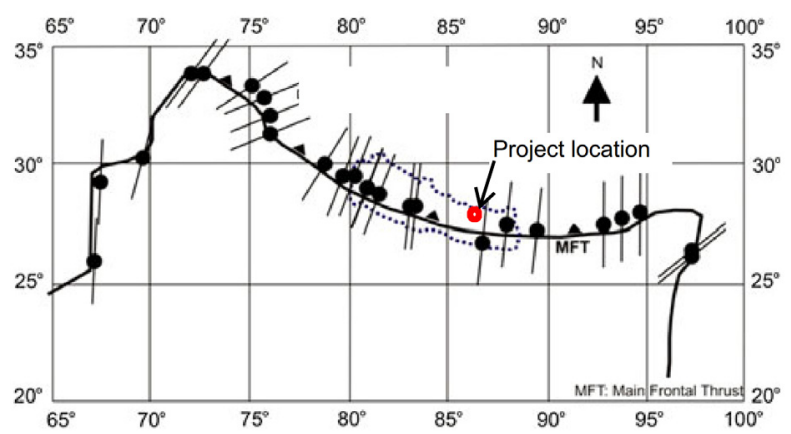

Figure 5: Approximate horizontal tectonic stress orientation (Panthi, 2012).

Note: Stress tensors and international boundary are not in scale

The general trend of the tectonic stress orientation in the Himalaya is NE-SW at the north-western part of the Himalaya and is more or less N-S at the south-eastern part of the Himalaya as shown in Figure 5 (Panthi, 2012). The trend nearby the project area appears to be in the

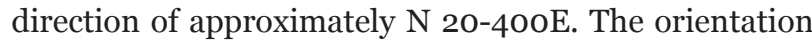
of the tectonic stress was based on (Panthi, 2012) and based on the information given by WSM (2016). On the other hand, the magnitude of the tectonic stress is difficult to estimate accurate enough and is therefore an issue of uncertainty.

As shown in Figures 4, Y-axis is aligned to the north direction. The normal stresses along $\mathrm{X}$ and $\mathrm{Y}$-axes and corresponding shear stress were calculated by resolving the assumed different magnitude of tectonic stress (Figure 6).

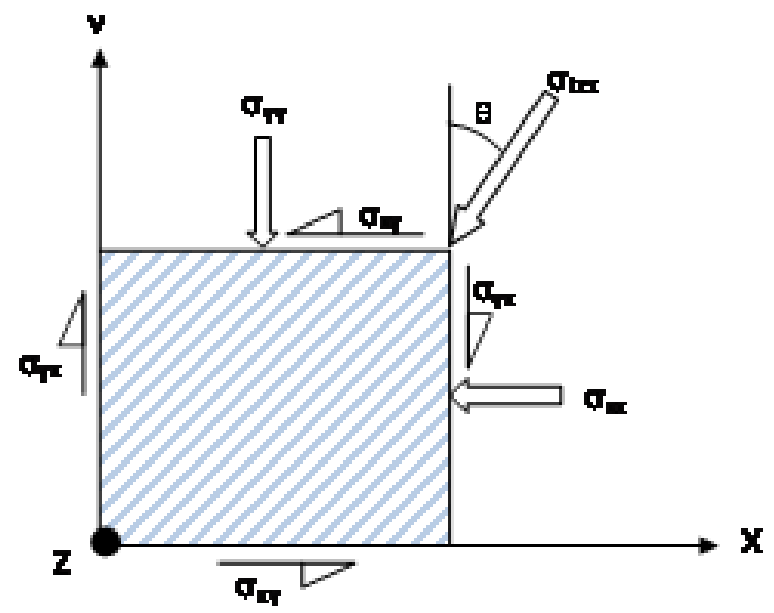

Figure 6: Resolving tectonic stress in $X$ and $Y$ directions

The total stresses along $\mathrm{Y}$ and $\mathrm{X}$-axes were calculated by using eq. 3 and eq. 4 , respectively. Since tectonic stress makes certain angle $(\theta)$ with $\mathrm{Y}$-axis (or X-axis), there will be shear stresses in $\mathrm{YZ}$ and $\mathrm{XZ}$ faces as shown in Figure 6 (the box shown in the figure has thickness along Z-axis). The shear stresses were assumed to be of the same magnitude in both faces and were estimated by using eq. 5 .

$$
\begin{aligned}
& \sigma_{y}=\sigma_{t e c} \cos ^{2}(\theta)+\sigma_{h} \\
& \sigma_{x}=\sigma_{t e c} \sin ^{2}(\theta)+\sigma_{h} \\
& \sigma_{y}=\sigma_{y}=\frac{\sigma_{t e c}}{2} \sin 2 \theta
\end{aligned}
$$

\section{Model validation}

First, the model was run with tectonic stress magnitudes of 10,15 and $20 \mathrm{Mpa}$ with varying orientation of N200E, N300E and N400E for each stress level. Since there are altogether nine combinations of magnitude and orientation of tectonic stresses it was necessary to run the $3 \mathrm{D}$ model nine times before it was validated. Output of the in-situ stresses form the modeling were compared with the measured in-situ stresses at different locations in terms of magnitude and orientations as shown in Figure 7, Figure 8 and Figure 9. 

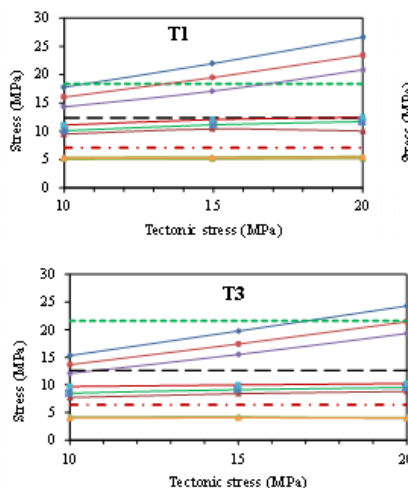

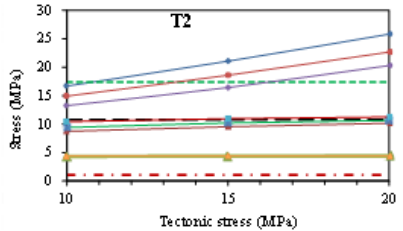

$$
\begin{array}{ll}
\longrightarrow \mathrm{S} 1-20 \mathrm{~d} & \longrightarrow \mathrm{S} 2-20 \mathrm{~d} \\
\longrightarrow \mathrm{S} 3-20 \mathrm{~d} & \longrightarrow \mathrm{S} 1-30 \mathrm{~d} \\
\longrightarrow \mathrm{S} 2-30 \mathrm{~d} & \longrightarrow \mathrm{S} 3-30 \mathrm{~d} \\
\longrightarrow \mathrm{S} 1-4 \mathrm{dd} 3-40 \mathrm{~d} & -\cdots \mathrm{S} 2-40 \mathrm{~d} \\
--\mathrm{S} 2-\text { measured } & -\cdots \mathrm{S} \text { S-measured }
\end{array}
$$

Figure 7: Results of simulated stresses at different tectonic stress level at the location where stress measurement were carried out by 3D-overcoring

Figure 7 shows in-situ principal stresses both from the model and from the measurement at three locations of the test tunnel. In the figure, for example S1-20d means major principal stress with tectonic stress orientation of N20oE and so on. As Figure 7 indicates, the major principal stress is very sensitive with respect to the change in tectonic stress magnitude and orientation than intermediate and minimum principal stresses. It is emphasized here that there are instances where S1 was found to be equal to the measured stress in locations $\mathrm{T} 1$ and $\mathrm{T} 2$ for each orientation under consideration indicating that there exist multiple choices of tectonic stress level in terms of magnitude. This situation demands verification of orientation in addition to magnitude. In this regard, the orientations of principal stresses are plotted in Figure 8 to assess their representativeness. Furthermore, the result of location $\mathrm{T}_{3}$ in Figure 7 does not match with the measured values, which is assumed to be due to the fact that according to SINTEF (2008) the stress measurement at this location was influenced by water ingress and therefore may not represent the actual stress state.
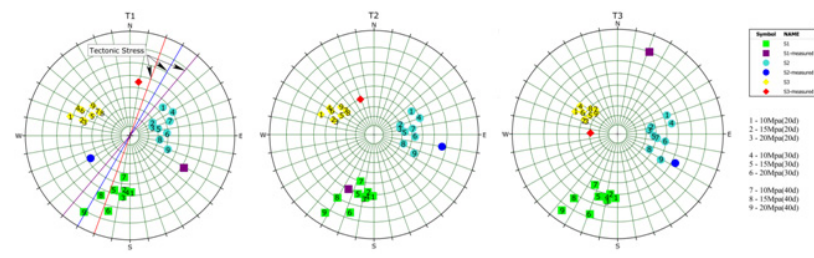

Figure 8: Stereo-plot of principal stress orientation in locations T1, T2 and T3 (Equal angle projection; Lower hemisphere)

In location $\mathrm{T} 2$, the orientation of principal stresses are scattered close to the measured ones, which indicates that the general trend of the orientations achieved from the model is closer to the measured values. On the other hand, the orientation of principal stresses in locations $\mathrm{T} 1$ and $\mathrm{T}_{3}$ are not matching with the measured orientation (Figure 8). However, the orientations of $\mathrm{S}_{2}$ and $\mathrm{S}_{3}$ in $\mathrm{T} 3$ are closer to measured ones and $\mathrm{S} 1$ is dipping in opposite direction. In addition to the test tunnel, minor principal stress from the model was also compared with the measured stress at the locations as given in Table 2.
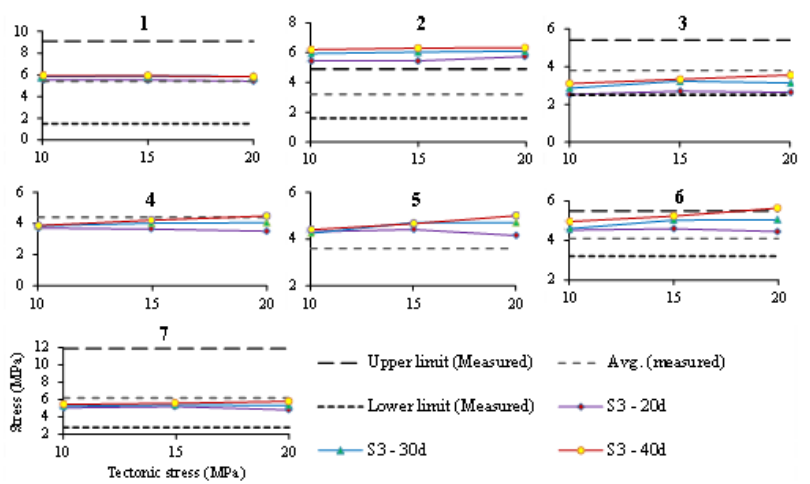

Figure 9: Minor principal stress (MPa) versus tectonic stress level (MPa) (Minor principal stress in vertical axis)

Figure 9 shows that minor principal stress in all seven locations seems not very sensitive to the change in tectonic stress magnitude and orientation. In conclusion, the general trend of the stress magnitude lies within the limit of measured stress except in locations 2 and location 5 where stress values from model shown higher result. In location 2, the stress values are closer to upper limit of measured ones, which may be due to its location closer to a crushed zone, which needs to be addressed in the model itself.

Finally, T2 was considered more representative with respect to the modeled stress state and was taken as decisive location where the major principal stress from the model are comparable in regards with both magnitudes and orientations. The orientation of $\mathrm{S} 1$ in Figure 8 for T2 shows that $\mathrm{S} 1$ in case of $15 \mathrm{MPa}$ tectonic stress with $\mathrm{N} 300 \mathrm{E}$ (point 5 in the rosette) seems very close to the measured orientation but magnitude was found not as very close as expected with the measured value (Figure 7). Considering this in mind, a model was run with $15 \mathrm{MPa}$ tectonic stresses having an orientation with N350E, which gave very good results (Figure 10).
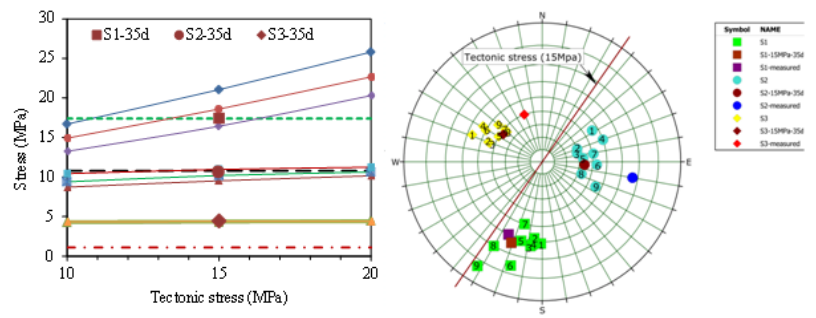

Figure 10: Verification of tectonic stress level and orientation in location $\mathrm{T} 2$

Figure 10 shows that the magnitude of S1 and S2 match well with the measured values. In addition, the orientation of $\mathrm{S} 1$ (both trend and plunge) also fits well within 50 accuracy. Hence, it was concluded that the tectonic stress magnitude is about $15 \mathrm{MPa}$ with its orientation of about $\mathrm{N} 35 \mathrm{OE}$. 


\section{In-situ Stress along the Topography}

The stress state of the project area was evaluated based on concluding made in Chapter 4; i.e. tectonic stress magnitude of $15 \mathrm{MPa}$ with orientation N35oE. The insitu stress state of the area was evaluated in terms of the magnitude of the minor principal stress, which is the major concern for unlined pressure tunnel. The stress values were assessed along the sections L-L, X-X, $\mathrm{Y}-\mathrm{Y}$ and L1-L1. These sections were selected in such a way that they incorporate most of the measurement locations, headrace tunnel alignment, cross valley as well as $3 \mathrm{D}$ effect on topographic slope (see Figure 2 for section location).

Figure 11 gives an overview of stress development along the valley side slope and illustrates stress attenuation caused by slope topographic effect. There are locations with tensile stress in the slope topography, which indicates that these locations are destressed. The figure also shows that there is stress concentration in the Tamakoshi valley. Since geometry of the model is gridded with different sizes, boundary effect can be seen in the interface of different rock mass groups, which can be avoided by using uniform grid sizes.

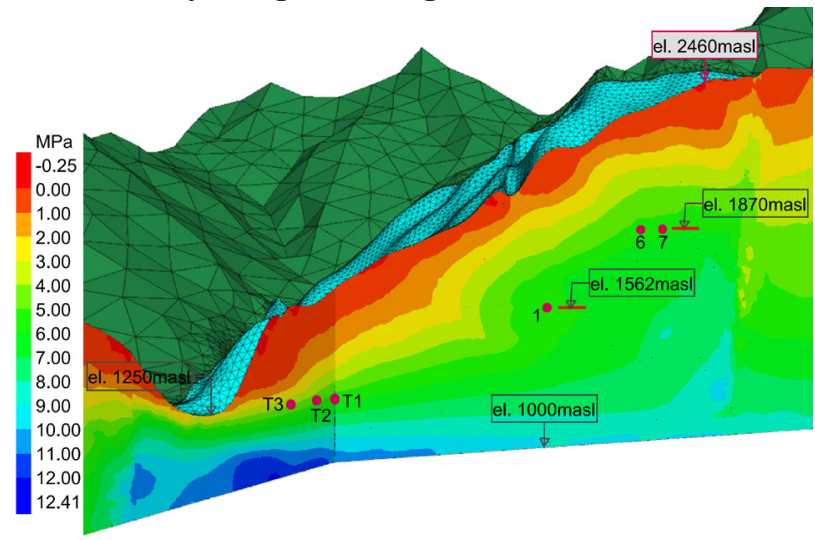

Figure 11: Minor principal stress along section L-L

(Note: Negative value is tensile stress and positive value is compressive stress)

Figure 12 shows the effect of Tamakoshi valley slope and upper reach of the Gongar valley slope in the stress development in the area. Both valleys are attenuating the stress and the stress situation is considerably influenced at locations 2 and location 4 .

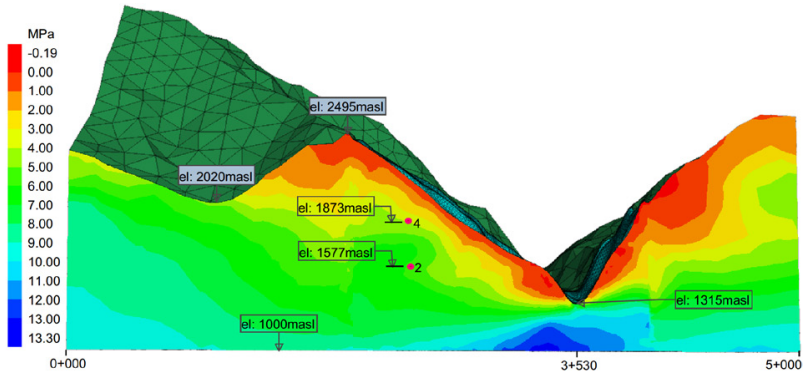

Figure 12: Minor principal stress along section X-X

As indicated in Figure 13, the lower reach of Gongar valley has much more influence on the stress situation than the upper reach. The figure also indicates that the minor principal stress is influenced at locations 1, location 2 and location 4. Hence, stress state along the valley slope cannot be visualized only based on the $2 \mathrm{D}$ assessment of the stress state, especially in those areas where there exists more than one valley slope, like in the Himalaya. Therefore, it is important that the stress state is evaluated using 3D model to get full view of slope topography effect as in Figure 14 with section L1-L1.

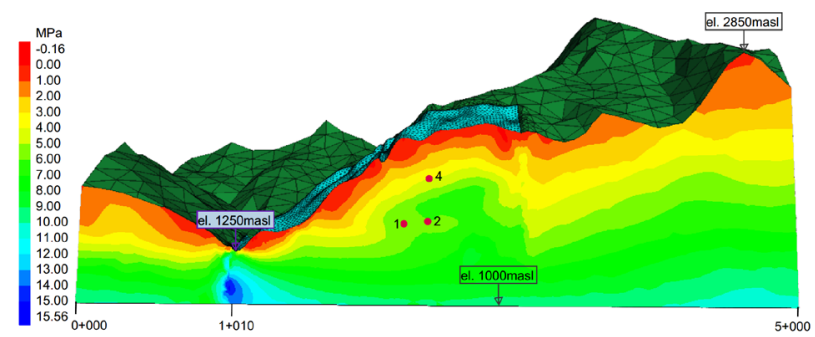

Figure 13: Minor principal stress along section $Y-Y$

One can clearly see on the Figure 14 that there is considerable influence in the stress state caused by both Tamakoshi valley and Gongar valley slopes. It addition, it was observed that the nose of the valley seems destressed considerably than at the bottom of the valley.

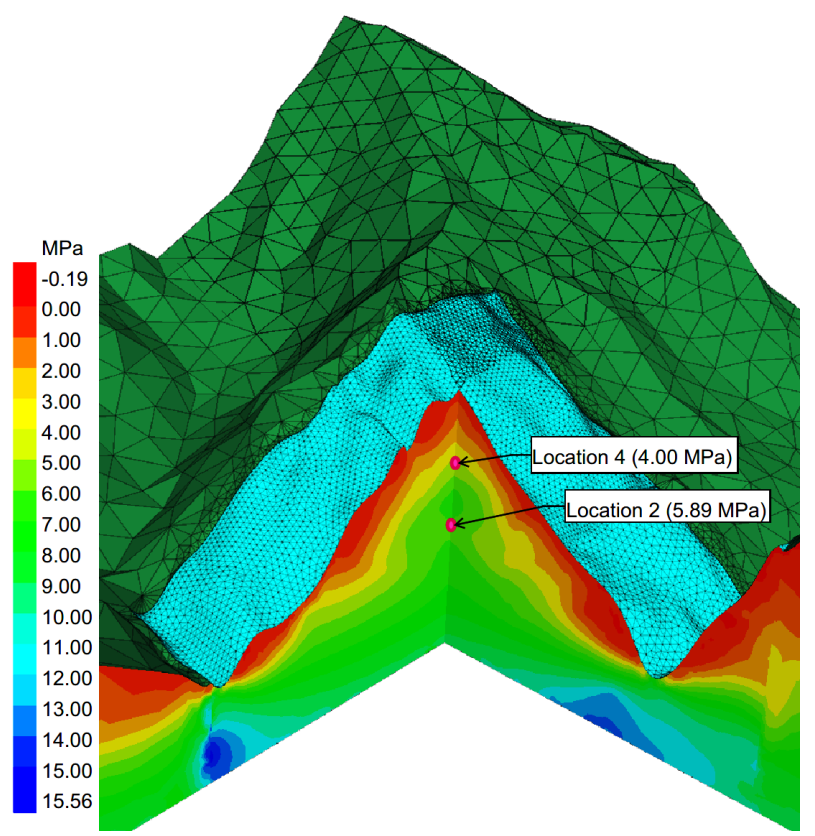

Figure 14: Sections in 3D showing the topographic influence in minor principal stress (section L1-L1)

Finally, a comparative study was carried out to assess the accuracy and discrepancy between the results from $3 \mathrm{D}$ model, measured by hydraulic fracturing and 3D-overcoring and overburden depth (Figure 15) for all the locations. As one can see in the figure, some of the measurements show considerable degree of discrepancy, which most likely may be due to changes caused by local shear bands and also due to measurement errors. 


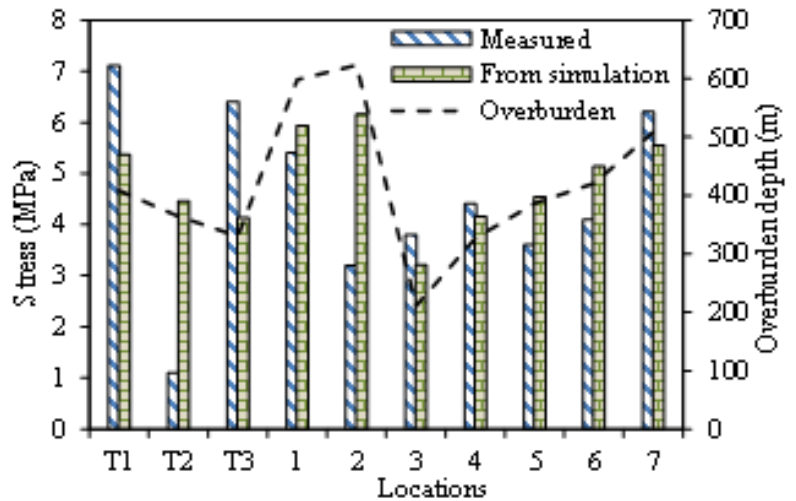

Figure 15: Minor principal stress at stress measurement locations

\section{Conclusions}

The simulation results of the stress state at Upper Tamakoshi suggests that the stress state in an area of interest can be modeled in $3 \mathrm{D}$ given that sufficient information on geotectonic environment and mechanical parameters of the rock mass are known. The simulation also suggests that outer reach of Upper Tamakoshi headrace system is very much influenced by the slope topography of two valleys. Hence, the $3 \mathrm{D}$ topographic effect has considerable impact in the selection of unlined pressure tunnel alignment and cannot be only based on the assessment of stress state in 2D. The output from the model also shows that the magnitude of minor principal stresses at different locations are on the higher side than the measured one, which is assumed to be due to the fact that the model is developed considering the rock mass as homogeneous material, which is not always the case. Hence, the model will be improved by introducing mapped shear bands along the headrace tunnel alignment.

\section{Acknowledgement}

The authors are grateful to the project management team of Upper Tamakoshi Hydroelectric Project for providing project data and information and giving permission to carry out research on this project, which will be a milestone in the use of unlined pressure tunnel concept in the Himalayan region. The paper represents a part of academic research and the results presented in the paper shall not be used as base material for the settlement of contractual issues of the project.

Er. Chhatra Bahadur Basnet is conducting his PhD research at the Department of Geology and Mineral Resources Engineering, Norwegian University of Science and Technology (NTNU), Norway. He holds MSc degree in Hydropower Development from NTNU. He has more than six years of working experience in planning, design, and construction supervision of number of hydropower projects in Nepal.
Corresponding E-mail: chhatra.basnet@gmail.com

Dr. Krishna Kanta Panthi is an Associate Professor in Geological Engineering at the Department of Geology and Mineral Resources Engineering, Norwegian University of Science and Technology (NTNU), Norway, since 2008. He holds PhD degree in Rock Engineering, $M S c$ in Hydropower Development and MSc in Tunneling. He is the author of many scientific papers published from very renowned journals published internationally. He has more than 20 years of experience in research, design and construction supervision of tunneling, hydropower and slope stability projects.

Corresponding E-mail: krishna.panthi@ntnu.no

\section{References}

Amadei, B. and Pan, E., 1995. Role of topography and anisotropy when selecting unlined pressure-tunnel alignment. Journal of geotechnical engineering, 121(12), pp.879-885.

Basnet, C.B. and Panthi, K.K., 2016. Unlined/Shotcrete Lined Pressure Tunnel Passing Through Himalayan Rock Mass - Design Review of Upper Tamakoshi Headrace Tunnel, Nepal. 9th Asian Rock Mechanics Symposium (ARMS9), Bali, Indonesia.

Bergh-Christensen, J., 1982. Design of Unlined Pressure Shaft at Mauranger Power Plant Norway. ISRM International Symposium. International Society for Rock Mechanics.

Bird, P., 1978. Initiation of intracontinental subduction in the Himalaya. Journal of Geophysical Research: Solid Earth, 83(B10), 4975-4987.

Broch, E., 1982. The development of unlined pressure shafts and tunnels in Norway, ISRM International Symposium. International Society for Rock Mechanics.

Broch, E., 1984. Unlined high pressure tunnels in areas of complex topography. International Water Power and Dam Construction, 36(11).

Buen, B., \& Palmstrom, A., 1982. Design and Supervision of Unlined Hydro Power Shafts and Tunnels with Head up to 590 Meters. ISRM International Symposium. International Society for Rock Mechanics.

Buen, B., 1984. Documentation unlined water conduits in Norway. Hard Rock Engineering, FHS, Oslo, Norway.

ITASCA, 2017. http://www.itascacg.com/software/flac3d

Jackson, J., McKenzie, D., Priestley, K. and Emmerson, B., 2008. New views on the structure and rheology of the lithosphere. Journal of the Geological Society, 165(2): 453-465

MSG, 2014. Hydraulic fracturing stress measurements in Upper Tamakoshi Hydroelectric Project. MeSySolexperts GmbH. Report no. 09.14.

MSG, 2015. Hydraulic fracturing stress measurements in Upper Tamakoshi Hydroelectric Project. MeSySolexperts GmbH. Report no. 02.14.

Panthi, K., 2012. Evaluation of rock bursting phenomena in a tunnel in the Himalayas. Bulletin of Engineering Geology and the Environment, 71(4): 761-769

Panthi, K.K., 2014. Norwegian Design Principle for High Pressure Tunnels and Shafts: It's Applicability in the 
Himalaya. Hydro Nepal: Journal of Water, Energy and Environment, 14: 36-40.

Reimer, W. and Bock, H., 2013. Report on the October 2013 project mission, Upper Tamakoshi Hydroelectric Project, Nepal Electricity Authority, Nepal.

Rocscience, 2017. https://www.rocscience.com

Rowley, D.B., 1996. Age of initiation of collision between India and Asia: A review of stratigraphic data. Earth and Planetary Science Letters, 145(1): 1-13.

Selmer-Olsen, R., 1969. Experience with unlined pressure shafts in Norway, Proc. Int. Symposium On Large Permanent Underground Openings, Oslo

Selmer-Olsen, R., 1974. Underground openings filled with high-pressure water or air. Bulletin of the International Association of Engineering Geolog y 9(1), pp.91-95.

SINTEF, 2008. Rock stress measurement at the Upper Tamakoshi Hydroelectric project. SBF IN F08112.

SINTEF, 2013. Rock stress measurement by hydraulic fracturing at Upper Tamakoshi Hydroelectric project, Nepal. SBF IN F08112.

Upreti, B., 1999. An overview of the stratigraphy and tectonics of the Nepal Himalaya. Journal of Asian Earth Sciences, 17(5): 577-606.

WSM, 2016. World stress map (http://www.world-stressmap.org/casmo/) 